international institute for

RESEARCH MEMORANDUM

\title{
WORLD ENERGY CONSUMPTION
}

J. P. Charpentier

December 1973 
Research Memoranda are informal publications relating to ongoing or projected areas of research at IIASA. The views expressed are those of the author, and do not necessarily reflect those of IIASA. 
、 


\section{World Energy Consumption}

$$
\text { J.P. Charpentier }
$$

The attached curves show the evolution (1960-2000) in different countries of:

- the global energy consumption;

- the electric energy consumption; and

- the production of nuclear energy for electric consumption.

These curves have been obtained by arithmetic average of different literature sources.

The unit conversion table was:

1 Mtec $=0.7 \quad M$ tep

1 Twh $=0.23 \mathrm{M}$ tep. 


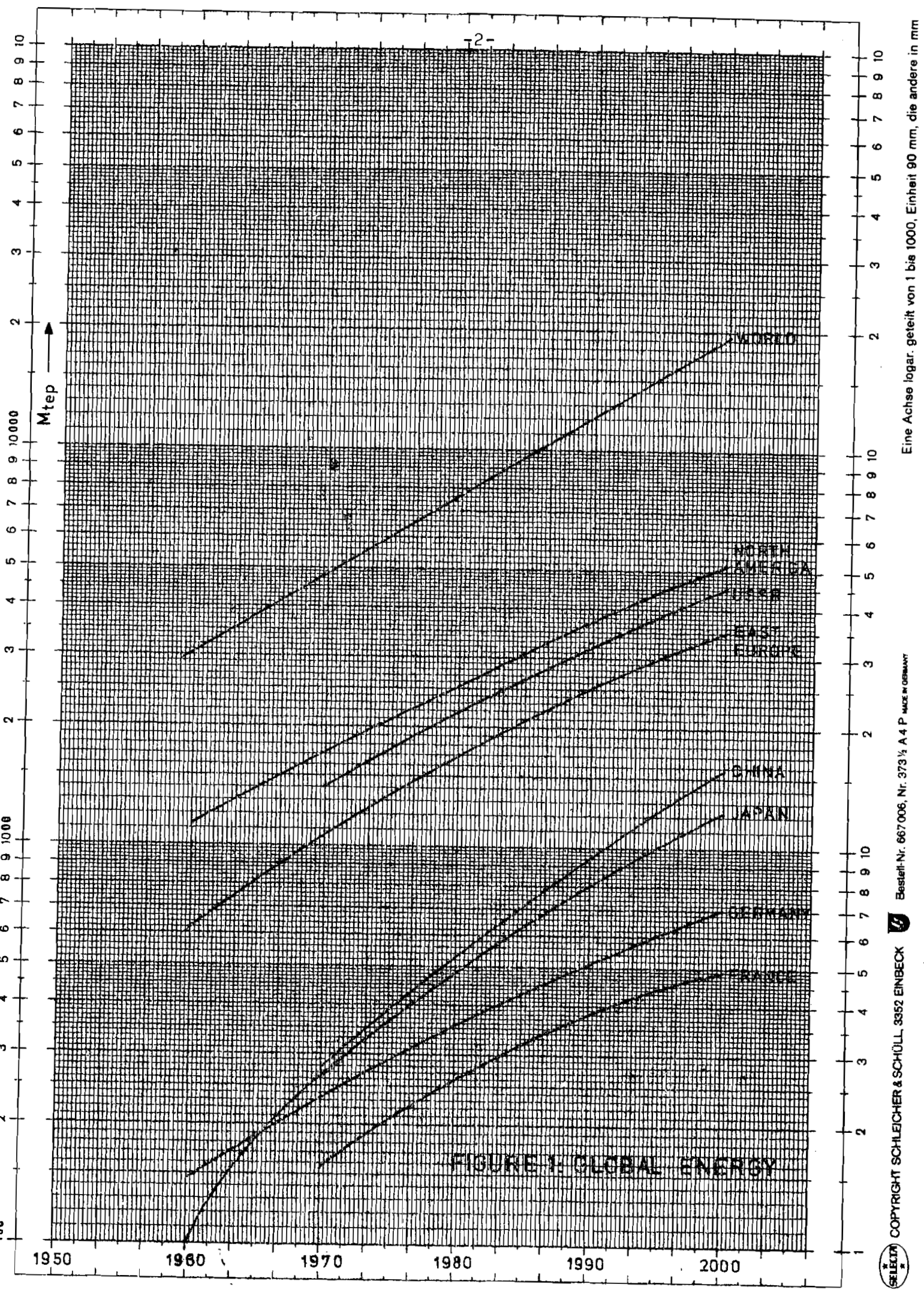




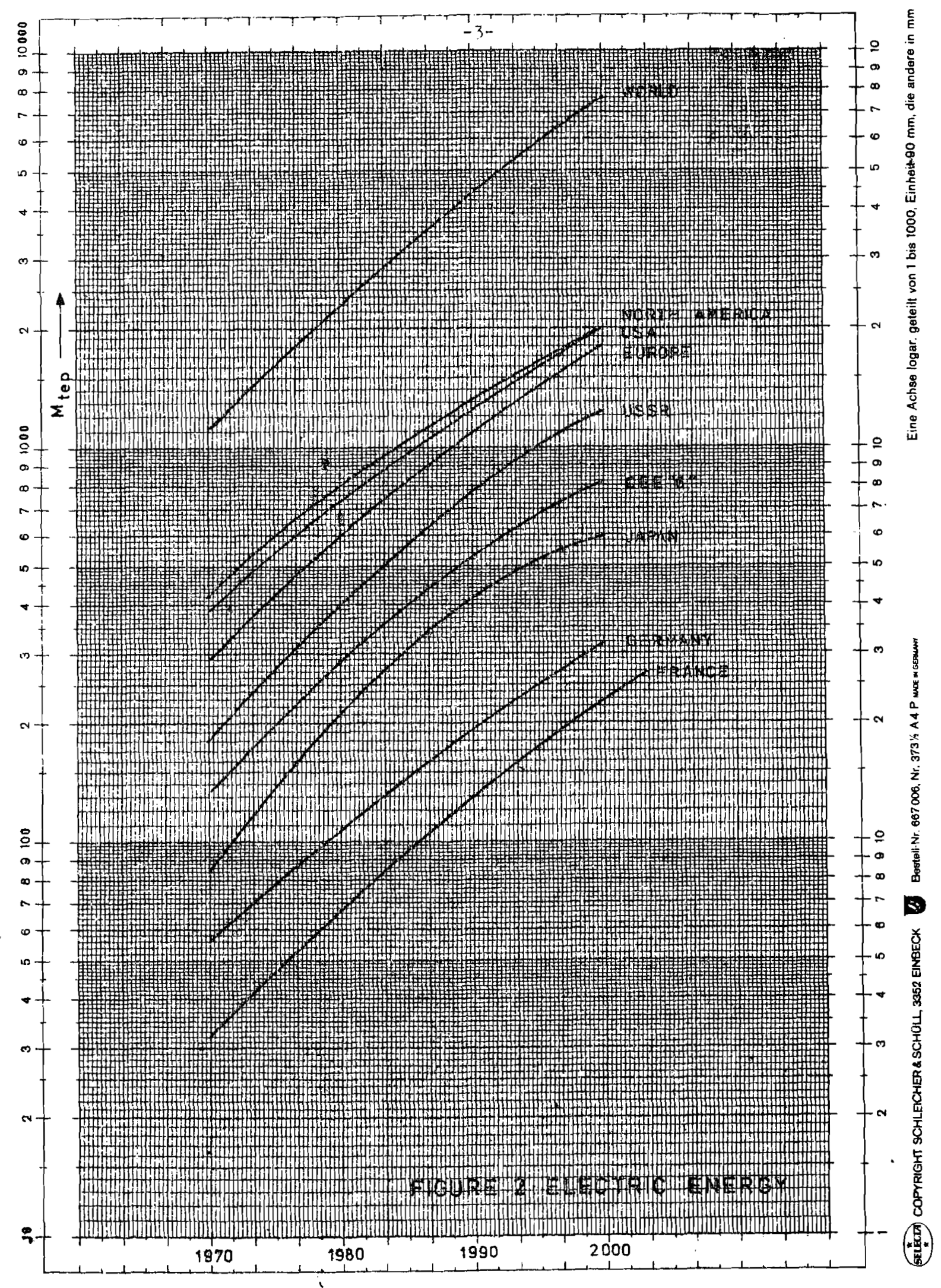




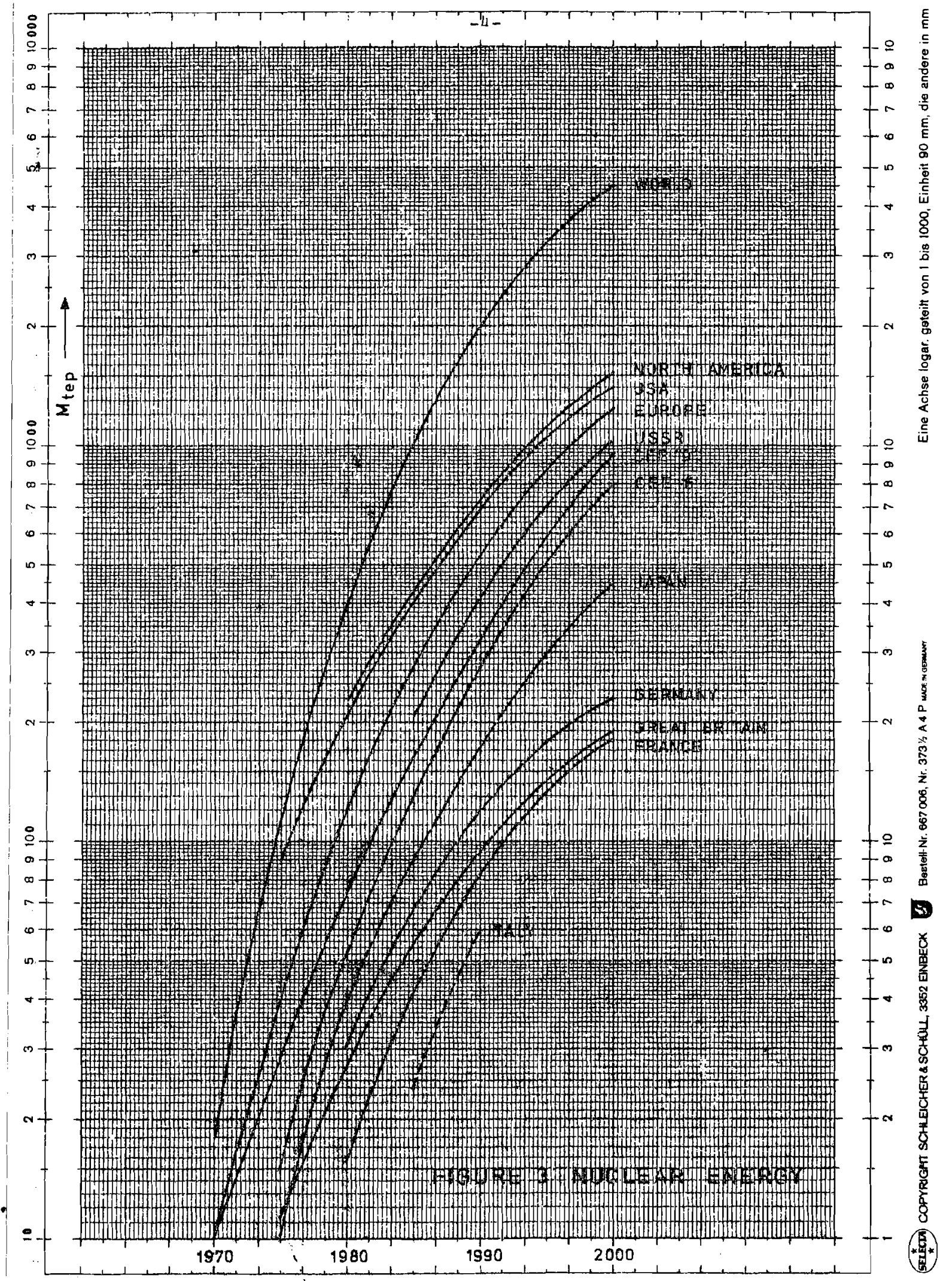


Table 1. Evolution of the partition between the consumption of electricity and nonelectricity energy.

\begin{tabular}{|c|c|c|c|c|c|c|}
\hline & \multicolumn{2}{|c|}{$\begin{array}{l}\text { Total Energy } \\
\text { Consumption } \\
10^{3} \text { tec }\end{array}$} & \multicolumn{2}{|c|}{$\begin{array}{l}\text { Electricity } \\
\text { Consumption } \\
10^{6} \text { kwh } \\
\left(10^{3} \text { tec }\right)^{*} 1\end{array}$} & \multicolumn{2}{|c|}{$\begin{array}{l}\text { Proportion of } \\
\text { the electricity } \\
\text { in the global } \\
\text { consumption of } \\
\text { energy }\end{array}$} \\
\hline & 1961 & 1970 & 1961 & 1970 & 1961 & 1970 \\
\hline Canada & 102558 & 192589 & $\left(\begin{array}{ll}110 & 927 \\
(36 & 939)\end{array}\right.$ & $\begin{array}{ll}201 & 300 \\
(67 & 033)\end{array}$ & $36 \%$ & $35 \%$ \\
\hline USA & 1481821 & 2278966 & $\left(\begin{array}{ll}883 & 750 \\
(294 & 289)\end{array}\right.$ & $\begin{array}{ll}1640 & 264 \\
(546 & 208)\end{array}$ & $20 \%$ & $24 \%$ \\
\hline Japan & 123403 & 332370 & $\begin{array}{ll}128 & 316 \\
(42 & 729)\end{array}$ & $\begin{array}{ll}350 & 590 \\
(116 & 746)\end{array}$ & $35 \%$ & $35 \%$ \\
\hline France & 116006 & 193034 & $\begin{array}{rl}76 & 583 \\
(25 & 502)\end{array}$ & $\begin{array}{ll}140 & 209 \\
(46 & 690)\end{array}$ & $22 \%$ & $24 \%$ \\
\hline Italy & 60945 & $144 \quad 102$ & $\begin{array}{cc}60 & 733 \\
(20 & 224)\end{array}$ & $\left.\begin{array}{ll}121 & 388 \\
(40 & 422\end{array}\right)$ & $33 \%$ & $28 \%$ \\
\hline U.K. & 260433 & 299143 & $\begin{array}{ll}145 & 954 \\
(48 & 602)\end{array}$ & $\begin{array}{ll}249 & 222 \\
(82 & 991)\end{array}$ & $19 \%$ & $28 \%$ \\
\hline USSR & 630774 & 1076861 & $\begin{array}{ll}327 & 537 \\
(109 & 070)\end{array}$ & $\begin{array}{rl}735 & 626 \\
(244 & 963)\end{array}$ & $17 \%$ & $23 \%$ \\
\hline Germany 1960 & 209772 & $337 \quad 154$ & 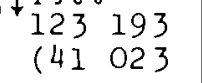 & $\begin{array}{ll}250 & 355 \\
(83 & 368)\end{array}$ & $20 \%$ & $25 \%$ \\
\hline
\end{tabular}

* $1: 10^{3} \mathrm{Kwh}=0.333 \mathrm{tec}$.

World Energy Supplies 61-70: U.N. 